\title{
Eficacia del programa de reinserción de pandilleros en el área geográfica de influencia de la unidad de salud de San Miguelito. Enero - junio 2002
}

Dr. Carlos Gamero

Jefe de Epidemiología del Hospital Nacional Zacamil del Ministerio de Salud Pública de El Salvador, San Salvad

Recepcionado: 20 abril, 2013 / Aceptado: 16 de julio, 2013

\section{RESUMEN}

La violencia generada por pandillas afecta a toda Centroamérica y especialmente a El Salvador. Es un problema social y contextual que se ha agudizado en la postguerra. Existe interés en buscar soluciones y se forman organizaciones que realizan labores de reinserción como el caso de Homies Unidos de El Salvador. Una organización para la noviolencia, de base comunitaria que desarrolla estrategiasde educación, prevención de situaciones de riesgo y recreación, principalmente en el área de Unidad de Salud de San Miguelito, por lo cual es importante saber cuáles han sido los resultados de este programa y que beneficios son percibidos por los pandilleros. El trabajo centra su atención en evaluar la eficacia del programa de reinserción de pandilleros de Homies Unidos a la vida social y productiva mediante un estudio descriptivo con enfoque cualitativo, utilizando como fuente de información los documentos oficiales del programa y la percepción de varios grupos como el Staff del programa, los mismos pandilleros y actores sociales locales. Los resultados del programa de reinserción son el mismo Staff de Homies Unidos. Los pandilleros reinsertados ven en el programa una oportunidad, pero su progreso al interior del programa no debe ser impuesto ni tampoco ser de extraños. Los actores sociales perciben el programa como una buena iniciativa que hay que divulgar y cimentar, con apoyo técnico y organizativo, como forma de intervenir en grupos de riesgo como las pandillas. El programa es eficaz, sin embargo requiere de trabajo integral de largo plazo y condiciones que la sociedad civil y las instituciones deben de complementar para obtener resultados de mayor impacto y cobertura. Este estudio recomienda realizar evaluaciones periódicas, fortalecer los niveles de coordinación y comunicación con actores sociales locales así como la administración del programa.

Palabras claves: pandillas, violencia, maras, reinserción, programa, San Miguelito.

\section{INTRODUCCIÓN}

En la actualidad nadie pone en duda que el fenómeno de las pandillas juveniles - ya sea callejera o estudiantil - constituye un problema serio en la vida social cotidiana del país. Más aún, a juzgar por el debate público que puede verse en los medios de comunicación, una parte de la población salvadoreña atribuye la problemática de la violencia o delincuencia a la existencia y actividad de las pandillas juveniles.

De hecho, una investigación de opinión pública realizada por el Instituto Universitario de Opinión Pública de la Universidad Centroamericana "José Simeón Cañas" (UCA) en julio de 1998, encontró que un poco más de la cuarta parte de la población adulta salvadoreña mayores de 18 años considera que el problema de las "maras" es el más urgente por atender en el combate de la criminalidad del país (IUDOP, 1998a).

Que los jóvenes se asocien en pandillas no es en sí mismo un hecho negativo, pero dadas las condiciones socioeconómicas, políticas y culturales de nuestro país, esa asociación entre los jóvenes ha tenido una mutación grave, creciendo de manera incontrolable e incorporando importantes dosis de violencia. De la misma forma en que la urbe ha ido invadiendo el campo $y$ ha crecido desmesuradamente, sin planificación, sin perspectiva de futuro y $\sin$ perspectiva humana; así este fenómeno parece escaparse de nuestras manos.

\section{MATERIALES Y MÉTODOS}

Tipo y diseño del estudio: Corresponde a un estudio descriptivo con enfoque cualitativo, el cual evalúa la eficacia del programa de reinserción de pandilleros Homies Unidos, en el área geográfica de influencia de la unidad de salud de San Miguelito.

Unidad de Análisis: La unidad de análisis es el programa Homies Unidos impulsado en el área geográfica de influencia de la Unidad de Salud de San Miguelito. El área geográfica donde se encuentra implementado el programa de Homies Unidos, abarca 
comunidades del área metropolitana de San Salvador, incluyendo las siguientes comunidades: Colonia Dina, Colonia Campanera, Valle Verde y Colonia. Zacamil. Del área geográfica de la Unidad de Salud de San Miguelito se incluyen las siguientes: Comunidades Tutunichapa II y IV.

\section{Las fuentes de información para el estudio fueron:}

a) Los documentos oficiales de Homies Unidos: memorias, informes, reportes trimestrales internos, reportes semestrales enviados al exterior, etc; b) Opiniones de los pandilleros y c) Opiniones de los actores sociales locales en torno a los resultados y aspectos generales del programa.

Las técnicas de recolección utilizadas fueron: entrevistas, revisión documental de informes de la organización y grupos focales con pandilleros. Las técnicas e instrumentos utilizados fueron los siguientes:

Ficha de Análisis de contenido: para sistematizar los resultados encontrados en los informes, memorias y otros datos proporcionados por el personal de Homies Unidos.

Guía de entrevista: utilizando encuesta semiestructurada, tanto en pandilleros, como en actores sociales locales relacionados con el programa.

Guía de Grupos focales: con el fin de recolectar información uniforme que permita captar y establecer los niveles de aceptación como forma de medir el impacto del programa en los pandilleros.

La información se recolectó de la siguiente manera:

- Se recolectó 1 ficha de análisis de contenido que concentra todos los resultados documentados del Programa Homies Unidos.

- Se realizaron 20 entrevistas a pandilleros dentro del programa de Homies Unidos.

- Se realizaron 2 grupos focales: uno con pandilleros reinsertados y uno con pandilleros no reinsertados.

- Se realizaron 6 entrevistas al Staff de Homies Unidos.

- Se realizaron 15 entrevistas a profundidad a actores sociales locales relacionados con los posibles resultados del programa.

\section{RESULTADOS}

\section{Factores que favorecen o dificultan el desarrollo del Programa de Homies Unidos:}

Factores que favorecen:

- Se cuenta con apoyo de organismos internacionales que dan financiamiento para el local y salarios del STAFF.

- La experiencia y rehabilitación personal.

- Mística de trabajo y trabajo de los voluntarios.

Factores que dificultan:

- No se cuenta con personería jurídica lo que hace difícil el incremento de voluntarios.

- Falta de recursos económicos.

- La desconfianza de la población.

- El desconocimiento del Programa y sus actividades.

- El abuso policial.

- La Discriminación por tatuajes.

- Desconocimiento de las necesidades del programa.

- Apoyo concreto de las organizaciones. - Falta de apoyo de instituciones gubernamentales.

\section{Principales resultados obtenidos con la reinserción de los pandilleros a la vida social}

Para los objetivos de este estudio, rehabilitado es aquel pandillero que ha ingresado al programa y ya no realiza actividades de violencia, delincuencia, y que ha continuado dentro del programa por más de 1 año, sin recaer en las situaciones antes expuestas. Los resultados observados de acuerdo a la percepción de los pandilleros se pueden resumir en los siguientes:

- Se cuenta con 6 rehabilitados completamente y son los miembros del Staff, que incluso están estudiando en universidades, acompañan a otras organizaciones en el diseño de material educativo.

- Se tiene oportunidad de capacitación y uso de computadoras.

- Conocimientos en prevención del VIH/SIDA y otros temas del área de la salud.

- Sensibilizar a los miembros, que a la larga puede contribuir ayudar a otros jóvenes a que salgan de la violencia.

- La recreación es uno de los puntos más resaltados del programa, ya que les permite relajarse y compartir inquietudes como grupo. 
- La atención de salud les favorece, ya que existe una enfermera capacitada dentro del Programa, que fue pandillera, y es el nexo con los servicios de salud, principalmente del Ministerio de Salud.

\section{Percepción de los pandilleros que han sido reinsertados en el Programa de Homies Unidos}

1) En cuanto a la percepción del conocimiento del programa de Homies Unidos, el $67 \%$ de los entrevistados manifiestan conocer el programa.

2) En cuanto a los resultados percibidos por ellos, los más relevantes son:

- Coordinación de actividades de prevención (VIH/SIDA).

- Ser nexo entre grupos de riesgo y programas de salud.

- Apoyo para investigaciones en grupos de pandillas.

Percepción que tiene los actores sociales sobre el programa de reinserción de Homies Unidos

\begin{tabular}{|c|c|c|}
\hline Actores & Factores que favorecent & Factores que dificultan \\
\hline $\begin{array}{l}\text { Sector Gubemamental } \\
\text { (U. de S.yPNC) }\end{array}$ & $\begin{array}{l}\text { - Voluntad de miembros. } \\
\text { - Conocimiento de pandillas. } \\
\text { - Aporo de USA: sede Los Ángeles. }\end{array}$ & $\begin{array}{l}\text { - Escaso presupuesto. } \\
\text { - Débil administración. } \\
\text { - Falta de personería legal. } \\
\text { - Discontinuidad de labores. }\end{array}$ \\
\hline Sector Municipal & $\begin{array}{l}\text { - Acercamiento local. } \\
\text { - Conocimiento de pandillas. }\end{array}$ & $\begin{array}{l}\text { - Discriminación. } \\
\text { - Desconocimiento actividades. }\end{array}$ \\
\hline ONGS & $\begin{array}{l}\text { - Acercamiento local. } \\
\text { - Conocimiento de pandillas. } \\
\text { - Trabajo operativo. }\end{array}$ & $\begin{array}{l}\text { - Débil administración. } \\
\text { - Falta de personeríal legal. } \\
\text { - No plan de trabajo. }\end{array}$ \\
\hline Organismos Intermacionales & $\begin{array}{l}\text { - Voluntad de miembros. } \\
\text { - Conocimiento de pandillas. } \\
\text { - Apoyo de USA: sede Los Ángeles. }\end{array}$ & $\begin{array}{l}\text { - Débil administración. } \\
\text { - Falta de personería legal. } \\
\text { - No plan de trabajo. }\end{array}$ \\
\hline Empresa Privada & - Conocimiento de pandillas. & $\begin{array}{l}\text { - Discriminación. } \\
\text { - Desconocimiento actividades. }\end{array}$ \\
\hline
\end{tabular}

En relación a la disposición de colaborar en iniciativas similares, el $87 \%$ están dispuestos a contribuir al desarrollo del programa. Referente a lo que los actores esperan que el programa sea para motivar su participación.

\section{DISCUSIÓN}

En el Programa de Homies Unidos, hablar en términos de rehabilitación o de reinserción se vuelve difícil y a veces hasta utópico, y esto se da en el sentido que ellos determinan que los resultados y mejoras en los jóvenes se complementan con el amplio deseo de cambiar, de reconocer "la necesidad de cambiar" que se traduzca en un cambio de actitud. Esto se va construyendo y no es de la noche a la mañana. Paralelamente a este esfuerzo, a través de la educación tanto de los pandilleros como de la población en general, se pueden ir aceptando los pandilleros como entes rehabilitados. La apariencia de pandilleros (en casos particulares) no se pierde: conservan sus tatuajes, conservan sus sobrenombres (muy característico en ellos) pero al interior han reconocido la necesidad de cambiar y de abandonar esa etapa en sus vidas, y esto no es identificado por la sociedad en general ni por las organizaciones comunitarias.

Disminuir la violencia entre pandillas y de pandillas para con la sociedad. No es extraño encontrar otras ONG's que hayan trabajado en el tema y no hallanobtenido resultados, ya que como los miembros de Homies Unidos mencionan: "Es difícil entrar y convencer sino has formado parte de ellos"

\section{CONCLUSIONES}

1) La eficacia programática no fue posible medirla ya que el programa no lleva registro ni sistema de información por el cual se comprueben los datos, aunque se debe resaltar que existe buena voluntad por mejorarlo.

2) El programa de Homies Unidos es eficaz, sin embargo requiere de trabajo integral de largo plazo y condiciones que la sociedad civil y las instituciones deben de complementar para obtener resultados de mayor impacto y cobertura.

3) La mejor muestra de desarrollo del Programa es el Staff, ya que ellos han sido pandilleros y hoy comandan esta iniciativa. La visualización del programa es clave y necesaria para contribuir a minimizar la discriminación y aumentar la credibilidad en el mismo.

\section{RECOMENDACIONES}

1) A los decisores políticos: apoyar la iniciativa y brindar alternativas de solución a las necesidades de estos grupos vulnerables de la sociedad, sobre todo sensibilizando a los cuerpos policiales y a la población en general, comenzando en las escuelas.

2) Al Ministerio de Salud Pública y Asistencia Social, continuar con la iniciativa de apoyar el componente de salud del programa de Homies Unidos, estableciendo lineamientos de coordinación más claros a los niveles locales. 
3) Al programa de Homies Unidos: continuar con los esfuerzos de sistematizar el programa de Homies Unidos, estableciendo plan de trabajo, indicadores y metas.

\section{BIBLIOGRAFÍA}

Álvarez G., K. L. Cómo trata el medio escrito "La Prensa Gráfica" y "El Diario de Hoy" el problema de la violencia de las maras: objetividad o sensacionalismo. San Salvador, 1999, $290 \mathrm{p}$.

Amaya, K. E. Actitudes de Padres de Familia, Alumnos y Maestras hacia aquellos estudiantes de bachillerato que forman parte de maras estudiantiles y pertenecen a instituciones educativas del Área Metropolitana de San Salvador. San Salvador, El Salvador. 1996.

Argueta, S. Y otros. Diagnóstico sobre los grupos llamados "maras" en San Salvador. Factores psicosociales que prevalecen en los jóvenes que los integran. El Salvador, 1991.
Código de Trabajo de El Salvador, San Salvador. 1997.

Cruz, J. M. Maras o Pandillas juveniles: los mitos sobre su formación e integración. San Salvador, 1999.

Cruz, José M. Solidaridad y violencia en las pandillas del Gran San Salvador. Más allá de la vida loca. IUDOP - Hommies Unidos - Radda Barnen. UCA Editores, 1ª Ed. 1988.

Homies Unidos. Reporte anual. 2001. Instituto Universitario de Opinión Pública. Encuesta sobre la juventud salvadoreña organizada en pandillas. San Salvador, El Salvador. 1997.

IUDOP. Maras y Pandillas en Centroamérica. Vol. IUCA publicaciones, San Salvador, 2001.

IUDOP. Sondeo sobre la juventud organizada en pandillas en San Salvador. El Salvador, 1997.

Mayorga, R. A. Influencia de la Televisión en las maras estudiantiles. San Salvador. 1994. 100 p. 